\title{
INDUCTION OF LABOUR;
}

COMPARISON OF OUTCOME OF PLANNED INDUCTION VERSUS EXPECTANT MANAGEMENT IN GESTATIONAL HYPERTENSION BETWEEN 36 TO 40 WEEKS

1. MBBS, FCPS

Woman Medical Officer Nishtar Hospital Multan.

2. MBBS, FCPS

Woman Medical Officer Nishtar Hospital Multan.

3. MBBS, FCPS

Consultant Gynaecologist PAC Hospital Kamra.

4. MBBS, FCPS

Assistant Professor

Nishtar Institute of Dentistry Multan.

Correspondence Address:

Dr. Aamir Furqan

Assistant Professor

Nishtar Institute of Dentistry Multan.

draamir2009@hotmail.com

Article received on:

02/12/2016

Accepted for publication:

25/02/2017

Received after proof reading: $06 / 04 / 2017$

\section{Dr. Nadia Taj', Dr. Rahat Akhtar', Dr, Sumera Mehnaz ${ }^{3}$, Dr. Aamir Furqan ${ }^{4}$}

\begin{abstract}
Objectives: To compare maternal outcome in planned induction of labor versus expectant management in pregnancy induced hypertension between 36 to 40 weeks of gestation. Study Design: Randomized controlled trial. Setting: Obstetrics and Gynecology Unit II of Nishter Hospital Multan. Period: January 2016 to July 2016. Materials and Methods: One hundred and thirty six (136) women with diagnosis of mild pregnancy induced hypertension, having gestational age 36 to 40 weeks were selected for this study. The selected patients were allocated randomly into two equal groups i.e. Group A (Induction group) \& Group B (Expectant group). The primary outcomes of this study were rate of cesarean section delivery and development of severe pre-eclampsia. Independent sample t-test was used to compare age between the groups. Chi-square test was used to compare age groups and study endpoints between the groups. Results: Mean gestational age at the time of delivery was $38.3 \pm 0.75$ weeks for group A and $39.2 \pm 0.55$ weeks for group B (P-value >0.05). Mode of delivery was 52 $(76.47 \%)$ patients by vaginal and $16(23.53 \%)$ by caesarean section in group $A$. While in group $\mathrm{B}$, out of 68 deliveries, $40(58.82 \%)$ patients delivered by vaginal and $28(41.18 \%)$ by caesarean section ( $p$-value $<0.05$ ). Regarding maternal outcomes, severe pre-eclampsia occurred in 05 $(7.35 \%)$ women of group A while in group B, it was noted $15(22.05 \%)$ women (p-value $<0.05)$. The final outcome was considered satisfactory in $76.47 \%$ patients in Induction group regarding vaginal delivery and severe pre-eclampsia while in Expectant group satisfactory outcomes were achieved in only $23.53 \%$ women ( $p$-value $<0.05$ ). Conclusion: Induction of labour is associated with improved maternal outcome in terms of caesarean section and pre-eclampsia in women with mild $\mathrm{PIH}$ beyond 36 weeks of gestation as compared to the expectant management.
\end{abstract}

Key words: Gestational hypertension, induction of labour, expectant management.

Article Citation: Taj N, Akhtar R, Mehnaz S, Furqan A. Induction of labour; comparison of outcome of planned induction versus expectant management in gestational hypertension between 36 to 40 weeks. Professional Med J 2017;24(4):522525. DOI: $10.17957 / T P M J / 17.3800$

\section{INTRODUCTION}

Pregnancy induced hypertension is an important pregnancy disorder and is associated with worse pregnancy outcomes. ${ }^{1,2}$ It complicates about 12 to $24 \%$ of all pregnancies. ${ }^{3}$ In many cases, it is presented as mild hypertension and mild proteinuria at term. In some rare cases severe complications occur e.g. eclampsia, preterm delivery, elevation in liver enzymes, low platelet count syndrome or even fetal death. ${ }^{1}$

The usual presentation is often after 32 week of pregnancy. Faulty implantation of placenta is considered to be the main cause of hypertensive disorders so immediate delivery is the only treatment of this disorder. Because during delivery placenta is removed and signs and symptoms of pregnancy induced hypertension also disappear with removal of placenta. ${ }^{4}$ The exact timing of induction is still debatable because early induction can increase the risk of caesarean sections and might deteriorate neonatal outcomes. According to HYPITAT-I trial, induction of labor at 37 weeks of pregnancy prevent the progression of hypertension and also reduces the number of caesarean sections. ${ }^{5}$ Induction of labour is cost effective and associated with better neonatal outcomes. ${ }^{6,7}$ There is little data available for the management of mild pregnancy induced hypertension from Pakistan. So this study was conducted to compare maternal outcome in planned induction of labor versus expectant 
management in pregnancy induced hypertension between 36 to 40 weeks of gestation.

\section{MATERIALS AND METHODS}

This Randomized controlled trial was directed in Obstetrics and Gynecology unit II of Nishter Hospital Multan. One hundred and thirty six (136) women with diagnosis of mild pregnancy induced hypertension were selected for this study. The study duration was from January 2016 to July 2016. Women having age 20 to 35 years at the time of presentation, having gestational age 36 to 40 weeks, primi gravida with singleton pregnancy, and having Bishops score $>6$ on vaginal examination were included. Women with diagnosis of pre-eclampsia i.e. those having systolic blood pressure $\geq 170 \mathrm{mmHg}$ and diastolic blood pressure $\geq 110 \mathrm{mmHg}$ at the time of presentation and those with diagnosis of diabetes mellitus along with pregnancy induced hypertension were excluded from this study.

The selected patients were located randomly into two groups i.e. Group A (Induction group) \& Group B (Expectant group), by using lottery method. In the Group A (Induction group), cervical ripening was stimulated with use of intracervical or intravaginal prostaglandins. Labour was induced by amniotomy and, if needed, augmentation with oxytocin was done. If delivery not occurs after a minimum of 8-12 hours of oxytocin administration and amniotomy then cesarean section was performed. While in Group B (Expectant group), patients were monitored until the onset of spontaneous delivery. Monitoring was consisted of assessment of fetal movements through electronic fetal heart rate (FHR) monitoring according to the local protocol. Maternal evaluation was done by frequent evaluation of blood pressure measurements and screening of urine for protein using a urine dipstick method.

The primary outcomes of this study were rate of cesarean section delivery and development of severe pre-eclampsia. The primary outcomes were considered satisfactory if patient had vaginal delivery and she did not develop severe preeclampsia and was considered unsatisfactory if patient had Caesarean section and she developed severe preeclampsia.

Sever pre-eclampsia was defined as blood pressure of patient approaching $>160 / 110 \mathrm{mmHg}$ with proteinuria exceeding $3+$ dipstick.

Data analysis was done using SPSS V19. Independent sample t-test was used to compare age between the groups. Chi-square test was used to compare age groups and study endpoints between the groups. P-value $<0.05$ was used to present significant difference.

\section{RESULTS}

One hundred and thirty six patients were included in this study, there were 68 patients in each group. The mean age of women in group $A$ was $23 \pm$ 4.35 and in group $B$ was $24 \pm 3.95$ years ( $P$-value $>0.05)$. Majority of the patients $53.68 \%$ were between 20 to 25 years of age. Mean gestational age at the time of delivery was $38.3 \pm 0.75$ weeks for group $A$ and $39.2 \pm 0.55$ weeks for group $B$ (P-value $>0.05$ ).

Mode of delivery was 52 (76.47\%) patients by vaginal and $16(23.53 \%)$ by caesarean section in group $A$. While in group $B$, out of 68 deliveries, $40(58.82 \%)$ patients delivered by vaginal and 28 (41.18\%) by caesarean section. Comparison of both groups on mode of delivery was statistically significant with $\mathrm{p}$-value $<0.05$.

Regarding maternal outcomes, severe preeclampsia occurred in 05 (7.35\%) women of group A while in group B, it was noted 15 (22.05\%) women ( $p$-value $<0.05)$. Seizures occurred in 2 (2.94\%) woman in group A and 5 (7.35\%) women in group $B$.

The final outcome was considered satisfactory in $76.47 \%$ patients in Induction group regarding vaginal delivery and severe pre-eclampsia while in Expectant group satisfactory outcomes were achieved in only $23.53 \%$ women ( $p$-value $<0.05$ ). 


\begin{tabular}{|c|c|c|c|}
\hline Name of Variable & Group A & Group B & P-value \\
\hline Mean Age $(Y)$ & $23 \pm 4.35$ & $24 \pm 3.95$ & $>0.05$ \\
\hline \multicolumn{4}{|l|}{ Distribution of Age } \\
\hline 20-25 Years & $38(55.88)$ & $35(51.47)$ & \multirow{3}{*}{$>0.05$} \\
\hline 26-30 Years & $21(30.88)$ & $23(33.82)$ & \\
\hline 31-35 Years & 09 (13.24) & $10(14.71)$ & \\
\hline
\end{tabular}

\begin{tabular}{|c|c|c|c|}
\hline Name of Variable & Group A & Group B & P-value \\
\hline \multicolumn{4}{|l|}{ Mode of Delivery } \\
\hline Vaginal & $52(76.47)$ & $40(58.88)$ & \multirow{2}{*}{$<0.05$} \\
\hline Caesarean & $16(23.53)$ & $28(41.18)$ & \\
\hline \multicolumn{4}{|l|}{ Maternal Outcomes } \\
\hline $\begin{array}{l}\text { Severe Pre- } \\
\text { eclampsia }\end{array}$ & $5(7.35)$ & $15(22.05)$ & $<0.05$ \\
\hline \multicolumn{4}{|c|}{ Final Outcomes Satisfaction } \\
\hline Yes & $52(76.47)$ & $40(58.82)$ & \multirow{2}{*}{$<0.05$} \\
\hline No & $16(23.53)$ & $28(41.18)$ & \\
\hline
\end{tabular}

\section{DISCUSSION}

Pregnancy induced hypertension (PIH) is one of the major causes of maternal mortality and morbidity in developing and developed countries. ${ }^{8}$ Pregnancy induced hypertensive disorders are responsible for $16.1 \%$ of all maternal deaths in developing countries and $9.1 \%$ in developed countries. $^{8}$ In Pakistan about $75.0 \%$ population is residing in rural areas where there is lack of antenatal monitoring facilities. Even in developed cities only $50.0 \%$ women have antenatal care and hospital delivery. ${ }^{9}$

Induction of labour and expectant conservative management are two routinely used modalities for the management of pregnancy induced hypertension at term. But data regarding the efficacy of these two methods is scarce. ${ }^{5}$ Induction of labour can prevent against the development of severe pre-eclampsia, birth asphyxia and maternal death but the risk of instrumental delivery or caesarean section might increase with this method. ${ }^{10,11}$ Many studies have favored induction and have concluded that it is associated with fewer caesarean rates. ${ }^{12,13}$ In this study we compared the induction of labour with expectant management of labour in women with mild PIH.

The mean age of patients in our study was $23 \pm 4.35$ years in group A and $24 \pm 3.95$ years in group B. Majority of the patients $53.68 \%$ were between 20 to 25 years of age in both groups. These results were very much comparable with Gondal KM et al ${ }^{14}$ study who had a mean age of 20 years but much lower than study of Koopmans $\mathrm{CM}$ et al ${ }^{5}$ who had a mean age of 30 and 31 years in group $A$ $\& B$ respectively. So, the results of this study had shown the increase risk of pregnancy induced hypertension in younger primigravida females.

In our study, Mean gestational age at the time of delivery was $38.3 \pm 0.75$ weeks in induction group and $39.2 \pm 0.55$ weeks in expectant group which is very much comparable to study of Koopmans $\mathrm{CM}$ et $\mathrm{al}^{5}$ who had found this as 38.7 weeks and 39.9 weeks respectively.

Some studies have clearly concluded that induction of labour at term does not upsurge emergency Caesarean section rates and intrapartum deaths. In large multi-centre trails by Gulmezoglu AM et $\mathrm{al}^{15}$ and Hannah ME et $\mathrm{al}^{16}$ policy of induction of labour did not increased the rate of caesarean section. Koopmans CM et al ${ }^{5}$ concluded that the rate of Caesarean delivery is reduced with elective induction of labour as compared to the expectant management. In our study, $23.53 \%$ patients were delivered by caesarean section in induction group while $41.18 \%$ in expectant management group. Our results correlated with studies mentioned above.

In this study, severe pre-eclampsia occurred in $7.35 \%$ women of induction group while in expectant group, it was noted in $22.06 \%$ women. Seizures occurred in $2.94 \%$ woman in group $A$ and $7.35 \%$ women in group B. similar results have been reported by other studies. According to the results of our study, induction of labour is associated with favorable maternal outcomes regarding normal vaginal delivery and prevention of severe pre-eclampsia.

\section{CONCLUSION}

Induction of labour is associated with improved maternal outcome in terms of caesarean section and pre-eclampsia in women with mild $\mathrm{PIH}$ 
beyond 36 weeks of gestation as compared to the expectant management.

Copyright@ 25 Feb, 2017.

\section{REFERENCES}

1. llekis JV, Reddy UM, Roberts JM. Review Article: Preeclampsia-A Pressing Problem: An Executive Summary of a National Institute of Child Health and Human Development Workshop. Reprod Sci. 2007;14(6):508-23.

2. Yücesoy G, Özkan S, Bodur H, Tan T, Çalışkan E, Vural $B$, et al. Maternal and perinatal outcome in pregnancies complicated with hypertensive disorder of pregnancy: a seven year experience of a tertiary care center. Arch Gynecol Obstet. 2005;273(1):43-9.

3. Mackillop L. High Risk Pregnancy: Management Options. J Obstet Gynaecol. 2008;28(4):465-.

4. Langenveld J, Broekhuijsen K, van Baaren G-J, van Pampus MG, van Kaam AH, Groen $\mathrm{H}$, et al. Induction of labour versus expectant monitoring for gestational hypertension or mild pre-eclampsia between 34 and 37 weeks' gestation (HYPITAT-II): a multicentre, open-label randomised controlled trial. BMC Pregnancy and Childbirth. 2011;11(1):50.

5. Koopmans CM, Bijlenga D, Groen H, Vijgen SM, Aarnoudse JG, Bekedam DJ, et al. Induction of labour versus expectant monitoring for gestational hypertension or mild pre-eclampsia after 36 weeks' gestation (HYPITAT): a multicentre, open-label randomised controlled trial. Lancet. 2009;374(9694):979-88.

6. Vijgen S, Koopmans C, Opmeer B, Groen H, Bijlenga D, Aarnoudse $\mathrm{J}$, et al. An economic analysis of induction of labour and expectant monitoring in women with gestational hypertension or pre $\square$ eclampsia at term (HYPITAT trial). BJOG: Int J Obstet Gynaecol. 2010;117(13):1577-85.

7. Bijlenga D, Koopmans CM, Birnie E, Mol B-WJ, van der Post JA, Bloemenkamp KW, et al. Health-related quality of life after induction of labor versus expectant monitoring in gestational hypertension or preeclampsia at term. Hypertens Pregnancy. 2011;30(3):260-74.

8. Khan KS, Wojdyla D, Say L, Gülmezoglu AM, Van Look PF. WHO analysis of causes of maternal death: a systematic review. Lancet. 2006;367(9516):1066-74.

9. Rehman MOU, Salah-Ud-Din MAS, Rehman S. Incidence Of Women Having Pregnancy Induced Hypertension In Karachi. Pak J Pharmacol. 2003;20:5-8.

10. Van Gemund N, Hardeman A, Scherjon S, Kanhai H. Intervention rates after elective induction of labor compared to labor with a spontaneous onset. Gynecol Obstet Invest. 2003;56(3):133-8.

11. Maslow AS, Sweeny AL. Elective induction of labor as a risk factor for cesarean delivery among low $\square$ risk women at term. Obstet Gynecol. 2000;95(6):917-22.

12. Wood S, Cooper S, Ross S. Does induction of labour increase the risk of caesarean section? A systematic review and meta $\square$ analysis of trials in women with intact membranes. BJOG: Int J Obstet Gynaecol. $2014 ; 121(6): 674-85$.

13. Stock SJ, Ferguson E, Duffy A, Ford I, Chalmers J, Norman JE. Outcomes of elective induction of labour compared with expectant management: population based study. BMJ. 2012;344:e2838.

14. Reiter L, Brown MA, Whitworth JA. Hypertension in pregnancy: the incidence of underlying renal disease and essential hypertension. Am J kidney diseas. 1994;24(6):883-7.

15. Gülmezoglu AM, Crowther CA, Middleton P, Heatley E. Induction of labour for improving birth outcomes for women at or beyond term. Cochrane Library. 2012.

16. Hannah ME, Ohlsson A, Farine D, Hewson SA, Hodnett ED, Myhr TL, et al. Induction of labor compared with expectant management for prelabor rupture of the membranes at term. New Eng $\mathrm{J}$ Med. 1996;334(16):1005-10.

\section{AUTHORSHIP AND CONTRIBUTION DECLARATION}

\begin{tabular}{|c|l|l|}
\hline Sr. \# & \multicolumn{1}{|c|}{ Author-s Full Name } & \multicolumn{1}{|c|}{ Contribution to the paper } \\
\hline 1 & Dr. Nadia Taj & Concieve idea, Data collection \\
2 & Dr. Rahat Akhtar & Study design, Data collection \\
3 & Dr. Sumera Mehnaz & Manuscript writing \\
4 & Dr. Aamir Furqan & Final approval, Proof reading \\
5 & Farman Ali & Data Analysis, Statistical analysis
\end{tabular}

